\title{
Development of a Mechatronic System for Demonstration Purposes
}

\author{
István GYÖRKOVÁCS, ${ }^{1}$ Zoltán FORGÓ ${ }^{2}$ \\ ${ }^{1}$ Sapientia EMTE, Faculty of Technical and Human Sciences - Târgu Mureș, Mechanical Engineering De- \\ partment. Târgu Mureș, Romania, gyorkovacs12@gmail.com \\ ${ }^{2}$ Sapientia EMTE, Faculty of Technical and Human Sciences - Târgu Mureș, Mechanical Engineering De- \\ partment. Târgu Mureș, Romania, zforgo@ms.sapientia.ro
}

\begin{abstract}
The aim of the paper is to present a modular system, with the help of which it is possible to reveal the structure and analysis of a mechatronic system, taking into account several disciplines that contribute to the structure of the system. The planned system will include devices from different disciplines, the operation and coordination of which will be observable. The designed system is a two-degree-of-freedom mechanism with a translational and a rotary joint. The movement of the joints are obtained by different types of energy converters (pneumatic, electric). The replacement of the different types of drives can be performed quickly and easily without drastically changing the system setup. The simulations are implemented using the MATLAB Simscape software package.
\end{abstract}

Keywords: mechatronic system, energy converters, joints, mechanism, simulation.

\section{Introduction}

Nowadays, mechatronic systems are so prevalent that they are found almost everywhere around us: we encounter them in the workplace and in our homes. They also play an essential role in various sectors of industry [1]. The mutually reinforcing integration of electronics, mechanical engineering and intelligent computer control can be observed in these systems [2,3].

We began with the question: how could a system be designed that would best illustrate the idea of mechatronics. Such a system would also have to show which fields of science are involved in mechatronics. Therefore, such a system would incorporate elements from mechanics, electrical / electronic devices and control systems [1-3]. The easiest implementation incorporating these ideas is a two-degree-of-freedom, serial robotic arm with a translational joint and a rotary joint. These joints would be driven by various energy converters and mechanisms, thus ensuring the demonstrability of the operation and the components. The ability of the joints to be equipped with mul- tiple power converters / mechanisms has also introduced a new design requirement: they need to be quick and easy to replace. So, the components that drive the joints should be quick and easy to detach and install without having to disassemble the main parts of the equipment.

\section{Equipment design}

The designed modular system should act as an illustrative tool in which the various components, mechanisms and energy converters that make up the system can be clearly observed and studied.

In the first phase of the design, the type and geometric dimensions of the modular system were determined. From this point of view, it includes a rotary and a translational joint and thus will be able to present as many types of drive as possible.

The first arm is connected to the base of the device by a translational joint, followed by a rotary joint. Their position is shown in Figure 1, which shows the kinematic diagram. Based on these, the body model of the demonstration equipment was created using the Autodesk Inventor software. 


\subsection{Design of the translation part}

The translation part of the designed equipment is based on a linear ball guide rail, which is fixed to the tabletop (1) with 8 M10 countersunk screws as shown in Figure 2. látható, és 8 darab M10-es süllyesztett fejü csavar segítségével van rögzítve az asztallaphoz (1).

The translational movement is realized by the slider (2) on the rail. The length of the rail (3) is $650 \mathrm{~mm}$, thus ensuring a travel distance of 500 $\mathrm{mm}$. Figure 2 also shows a stand (4) at the end of the rail. The purpose of this stand is to fix the various energy converters. In order to support the rest of the mechanism, a stand (5) has been placed on the slider also.

The size of the lower and upper plates are the same as the dimensions of the slider.

The movement of the translation part can be realized with four types of energy converter:

- pneumatic drive;

- ball screw drive;

- rack drive;

- swivel arm drive.

Taking account of the paper length, of the listed drive types, only the ball screw drive will be shown, and the simulation was also performed with this drive type. In the case of a pneumatic drive, the movement of the slider is ensured by a double-acting cylinder with a stroke length of $500 \mathrm{~mm}$.

In the case of a rack and pinion drive, the rotary motion of the stepper motor is converted into a translational motion by a gear rack pair. In the case of a rotary arm drive, a driver and a driven arm are responsible for converting the rotational movement of the stepper motor.

\section{Ball screw drive description:}

In the case of the second type of drive (Figure 3) a stepper motor (1) converts the electric energy. The rotational motion of the motor is converted into a translational motion by a ball screw-ball nut pair. The selected ball screw (2) is a $600 \mathrm{~mm}$ long (the threaded part is $513 \mathrm{~mm}$ ), $12 \mathrm{~mm}$ nominal diameter, $2 \mathrm{~mm}$ ball diameter, right threaded, rolled ball screw with precision class $\mathrm{C} 7$. The ball nut (3) has a RSH type threaded mounting option. The ball screw-ball nut pair is installed in the system as shown in Figure 3. The ball nut (3) is connected to the connecting part (4) via an M10 screw connection and is connected to the stand (9) on the slider by two, $20 \mathrm{~mm}$ long and $\emptyset 25 \mathrm{~mm}$ steel pins (8). The ball screw (2) passes through the

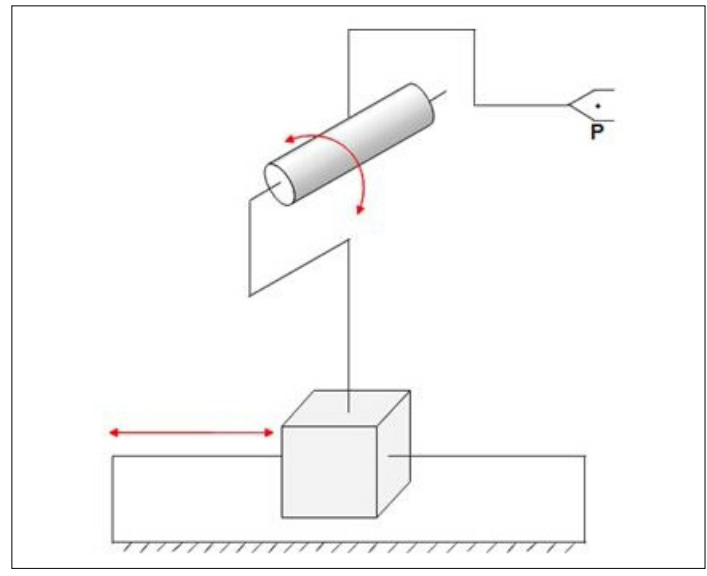

Figure 1. Kinematic diagram of the equipment.

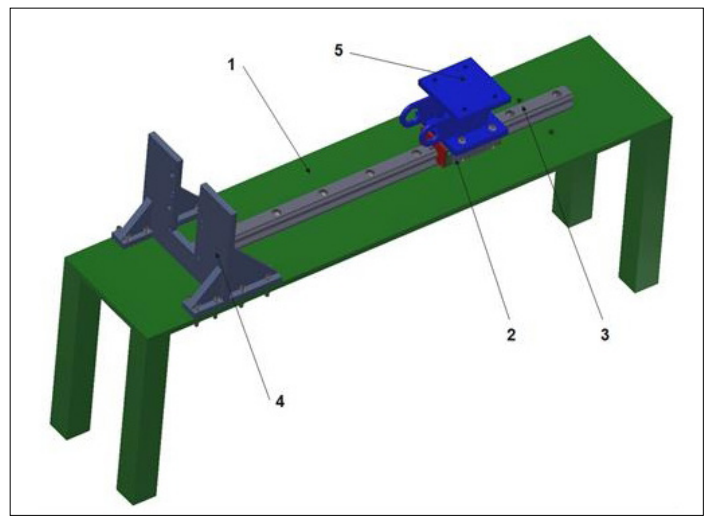

Figure 2. Structure of the translation part: 1-table top, 2-slider, 3-rail, 4-drive mounting stand, 5 -slider stand.

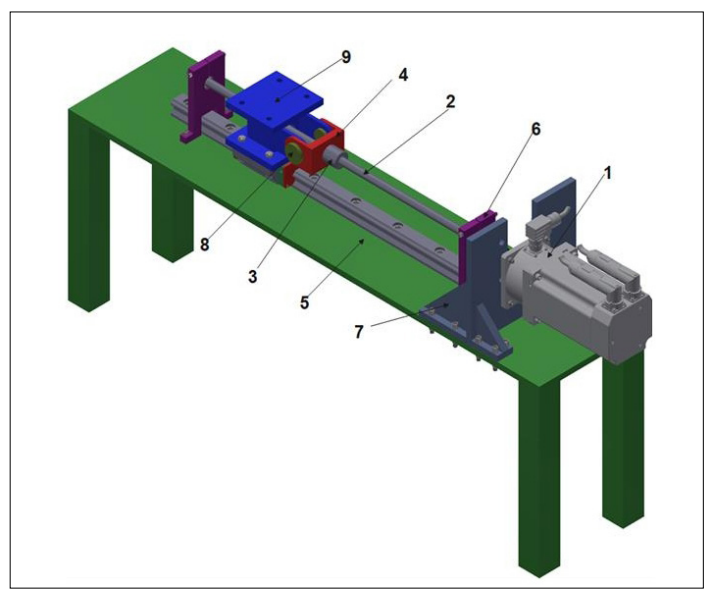

Figure 3. Model of the translation part with ball screw drive: 1-stepper motor, 2-ball screw, 3-ball nut, 4- connecting part, 5-table top, 6-bearing clamp, 7-drive mounting stand, 8-steel shaft, 9-stand on the slide. 
center of the stand (9). For this purpose, there is a $28 \mathrm{~mm}$ diameter hole on the stand. At the spindle (2) are used bearings at both end of the threaded part, the bearing clamps (6) are fastened to the tabletop (5) with two M5 screws. The bearings are clamped with an M5 screw, and their linear movement is prevented by the shoulders formed on the bearing holder (6) and the ball screw (2).

The shaft of the stepper motor (1) is connected to the ball screw via an Oldham coupling (10). This clutch allows a small radial deviation between the motor shaft and the ball screw and takes up less space than other types of clutch.

\subsection{Design of the rotating part}

The rotational part of the designed device, as shown in Figure 4, consists of two main components: the base (5) and the arm (1).

The base (2) is a $210 \mathrm{~mm}$ long, $140 \mathrm{~mm}$ wide, 10 $\mathrm{mm}$ thick aluminum plate, and a $100 \mathrm{~mm}$ long, $30 \times 30 \mathrm{~mm}$ aluminum block. The position of the latter block on the aluminum plate is determined to be in the middle when the base (5) and the arm (1) are mounted on the stand (6) on the slider. As can be seen in Figure 4, the surface of the base (5) is larger than the surface of the stand (6) on the slider. This is because the energy converters driving the rotating part should be fixed. The arm (1) is connected to the base via two ball bearings with an internal diameter of $15 \mathrm{~mm}$, where the rotary joint is formed. The arm (1) is made of a $300 \mathrm{~mm}$ long, $20 \times 30 \mathrm{~mm}$ aluminum closed section.

The rotary part drive is made with three types of energy converter or mechanism:

- pneumatic drive with a cylinder;

- stepper motor drive;

- stepper motor drive with timing belt.

Of the rotary drive types, only the stepper motor drive will be shown, because this drive type was mounted on the unit during the simulation. In the case of a pneumatic drive, the rotation of the rotary arm is ensured by a $150 \mathrm{~mm}$ stroke double-acting cylinder. In the case of a timing belt drive, the rotational movement of the stepper motor is transmitted to the rotary joint via a timing belt transmission.

\section{Description of stepper motor drive:}

In this type of drive (Figure 4) the rotation of the motor (3) is transferred to the axis of the rotary joint with a clutch, so that the rotational speed of the arm (1) is equal to the rotational speed of the rotor of the stepper motor (3).
The stand (4) is made of a $5 \mathrm{~mm}$ thick aluminum plate. The shaft of the stepper motor (3) and the shaft of the rotary joint are connected by means of a $6 \mathrm{~mm}$ inner diameter Oldham clutch (2): this type of clutch absorbs angular and parallelism errors between the two axes.

\section{Equipment simulation}

The device was simulated in the MATLAB Simulink environment, where the simulated conditions reflect the equipment that you would encounter in the real environment during its operation.

During the simulation, the characteristic point (P) of the presented mechanism is moved along a vertical line (Figure 5).

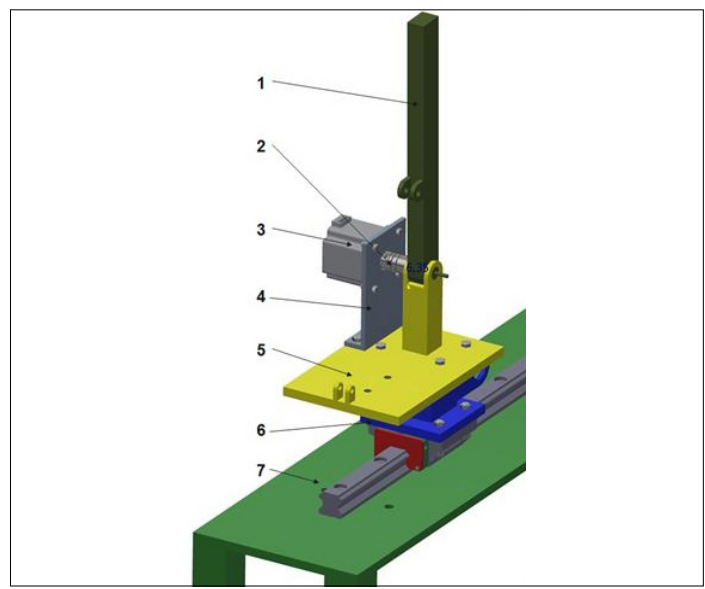

Figure 4. The rotating part of the unit is equipped with a stepper motor drive: 1-lever, 2-clutch, 3-stepper motor, 4-motor holder, 5-rotary joint base, 6-slider stand, 7-table top.

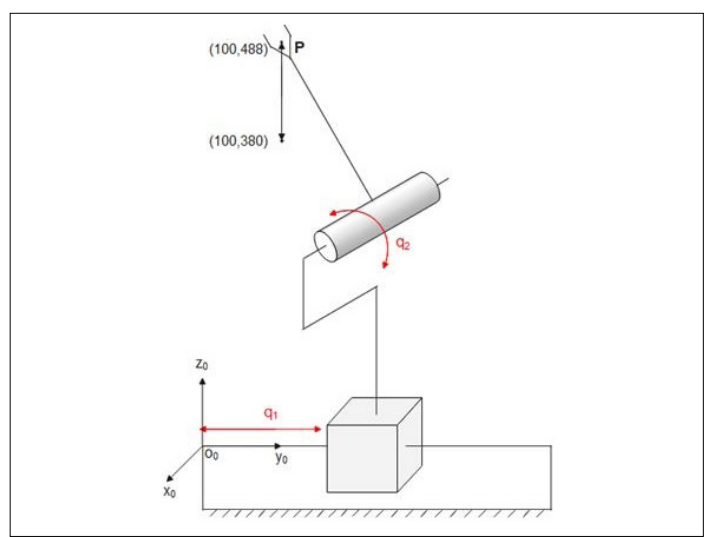

Figure 5. The schematic of the device, with the vertical path of the characteristic point (P). 
Table 1. Denavit-Hartenberg parameters

\begin{tabular}{|c|c|c|c|c|}
\hline $\mathbf{D H}$ & $\boldsymbol{a}_{\mathbf{i}-\mathbf{1}}$ & $\mathbf{a}_{\mathbf{i}-\mathbf{1}}$ & $\boldsymbol{\theta}_{\mathbf{i}}$ & $\mathbf{d}_{\mathbf{i}}$ \\
\hline 1 & $-\pi / 2$ & 0 & $-\pi / 2$ & $\mathrm{l}_{3}+\mathrm{q}_{1}$ \\
\hline 2 & $\pi / 2$ & $\mathrm{l} 1$ & $0+\mathrm{q}_{2}$ & 0 \\
\hline
\end{tabular}

\subsection{Calculations required for the simulation}

For the characteristic point to pass along the vertical line shown in Figure 5, both joints of the device must be in motion, so that the joint parameters q1 and q2 will be constantly changing. Their change will be described by an equation, which can be determined by the inverse geometric problem of the mechanism.

To solve the inverse geometry problem using the Denavit-Hartenberg convention, the parameters shown in Table 1 will be used in the modeling.

By substituting the parameters in formulas (1), (2), (3), (4) and performing the multiplications, and expressing the variables $q_{1}$ and $q_{2}$ from the equations, the coordinates of the characteristic point (5) can be determined. Substituting the system dimensions $\left(l_{1}=209 \mathrm{~mm}, l_{2}=290 \mathrm{~mm}\right.$, $l_{3}=0 \mathrm{~mm}$ ), the parametric equations of the joint variables were calculated (6), which form the basis for the control of rotary and translational joints in the Simulink model.

$$
\begin{aligned}
& {[\boldsymbol{T}]=\boldsymbol{T}_{R}\left(\boldsymbol{x}_{0},-\frac{\pi}{2}\right) \cdot \boldsymbol{T}_{T}\left(\boldsymbol{x}_{0}, 0\right) \cdot \boldsymbol{T}_{R}\left(\boldsymbol{z}_{1},-\frac{\pi}{2}\right) \cdot \boldsymbol{T}_{T}\left(\boldsymbol{z}_{1},\left(l_{3}+q_{1}\right)\right.} \\
& {[\boldsymbol{T}]=\boldsymbol{T}_{R}\left(\boldsymbol{x}_{1}, \frac{\pi}{2}\right) \cdot \boldsymbol{T}_{T}\left(\boldsymbol{x}_{1}, l_{1}\right) \cdot \boldsymbol{T}_{R}\left(\boldsymbol{z}_{2}, q_{2}\right) \cdot \boldsymbol{T}_{T}\left(\boldsymbol{z}_{2}, \mathrm{C}\right.} \\
& { }_{2}^{0}[\boldsymbol{T}]={ }_{1}^{0}[\boldsymbol{T}] \cdot{ }_{2}^{1}[\boldsymbol{T}] \\
& { }_{r}{ } P={ }_{2}^{0}[\boldsymbol{T}] \cdot{ }^{2} r P \\
& q_{1}=\mathbf{y}_{P}-l_{3}-l_{2} \cdot \sin \left(\arccos \left(\frac{\mathbf{z}_{P}-l_{1}}{l_{2}}\right)\right) \\
& q_{1}=\boldsymbol{y}_{P}-290,488 \cdot \arccos \left(\frac{\mathbf{z}_{P}-l_{1}}{l_{2}}\right) \\
& q_{2}=\arccos \left(\frac{\boldsymbol{z}_{P}-209,512}{290,488}\right)
\end{aligned}
$$

\subsection{The simulation process}

The 3D model created in Autodesk Inventor software can be transferred to the MATLAB Simulink environment using the Simscape Multibody Link software package, where the connections between different parts and subassemblies can be observed and studied, and the operation of the equipment can be simulated.

During the simulation, the ball screw solution is installed as the driver of the translation joint, and the stepper motor is located on the rotary joint. The Simscape MultiBody model of this system is shown in Figure 6. The simulation was performed by introducing the equations of motion for the rotary (R-joint) and translational (T-joint) joints. As result, geometric control of the motion is provided from the input, while the dynamic force and torque required for the motion is calculated by the system.

The middle blue area, called Mechanism, contains the base of the system and the arrays of its components (the arrays contain the components that do not move relative to each other):

- the array, which includes the table, the rail, and the stand at the end of the rail;

-the translation joint connecting the rail and the slider that must be operated by equation (6) using parameter $q_{1}$;

- the slider assembly, which includes the slider, the stand on the slider and the base of the rotating part;

-the rotary joint, which is integrated between the base of the rotary part and the rotary arm, is driven by equation (6) with parameter $\mathrm{q}_{2}$; - end arm array.

In the upper area is the model of the drive of the rotating part, which in this case is a stepper motor drive. The components of the drive and their connection can be observed:

-a stepper motor support array comprising a model of the stepper motor, the stepper motor stand and the Oldham clutch;

- a cylindrical joint secures the axis of the rotary joint and a mounted on the shaft of the stepper motor.

In the lower area there is the drive of the translation part, which in this case is the ball screw drive.

There also, the components of the drive can be observed:

-the array, where the stepper motor and the Oldham clutch are located;

-the bearing clamp blocks 1 and the bearing clamp blocks 2 contain the two bearing clamps and the associated bearings;

-in the ball nut assembly block, the ball nut and the intermediate part are located, thus connected to the slider;

-the ball screw is located in the block with the ball screw bearings; 


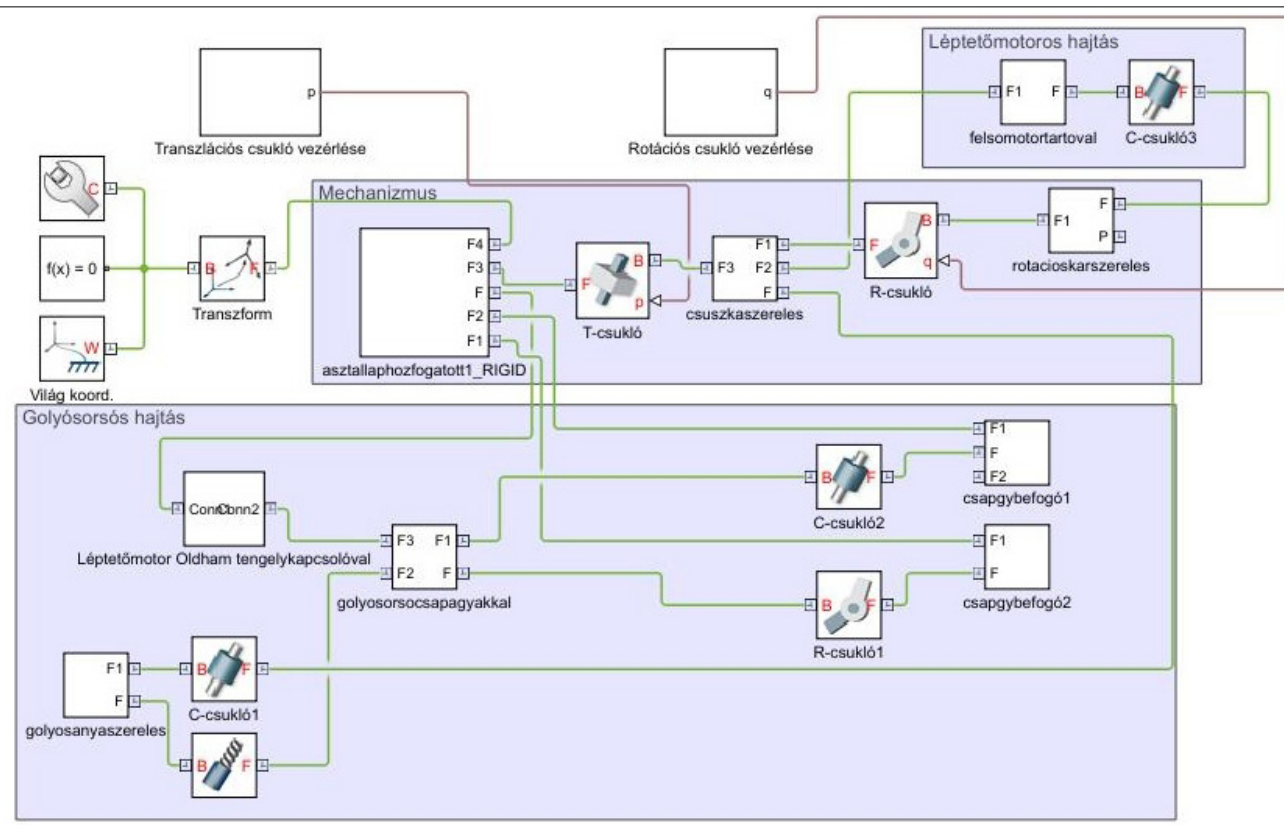

Figure 6. The Simscape MultiBody model.

-the ball screw and the ball nut are connected via a screw joint.

It should also be mentioned that during the simulation only the ball screw drive and the stepper motor drive were examined, however, in the case of the Simscape model it is possible to change the type of drives of the translational and rotary part, as the model is modular. As can be seen in Figure 6 a subsystem called Rotary Joint Control, which induces the motion, is connected to the rotational joint (R-joint) via the input $q$. The translation joint (T-joint) is connected via input $p$ to a subsystem called the Translational Joint Control, which determines its movement. In these two subsystems, the equations of the hinge variables $\mathrm{q}_{1}$ and $\mathrm{q}_{2}$ defined in Equation (6) are implemented.

\subsection{Evaluation the simulation}

After completing the simulation, we have the opportunity to display various kinematic and dynamic parameters that determine the operation of the system. For example, the displacement, velocity, acceleration of the characteristic point in relation to the rectangular reference system, the whole time of the simulation, or even the displacement, velocity, acceleration of the joints, the torques / forces required for the operation of the system. The results can be displayed as a numerical value or graphically.

\section{Conclusions}

In conclusion, it is possible to design and simulate a modular system, with which it is possible to present and study the structure and composition of a mechatronic system. The requirements prescribed during the design were met: the drive of the joints with several energy converters and mechanisms, the quick and relatively easy replacement of the drives. During the design and simulation of the device, the advantages and disadvantages of the different drive types, which have also been described in the literature, have been confirmed.

In the case of a pneumatic drive, the advantages are: simple implementation of straight-line movements, less sensitive to disturbing effects, flexible (mechanical shock absorption capacity). Disadvantages: relatively high energy costs, smooth, constant speed movements, cannot be produced regardless of the load.

The advantages of a rack-and-pinion drive are mechanical simplicity, high load capacity, while the disadvantages are inaccurate control due to possible backlash and lower efficiency.

In the case of a ball screw drive, high accuracy, rigidity, good efficiency, low friction between the rolling elements are an advantage, while a higher acquisition cost can be a disadvantage. 
The advantage of a rotary arm drive is the simple operation and then the high load on the motor when starting, or the disadvantage that the linear speed of the slider requires proper control of the rotary shaft motor.

In the case of rotary motion, the advantages of the pneumatic drive are simple reversal of rotation, simple design of the control system, it can withstand possible overload without damage, while the disadvantages are difficult to achieve rotational motion, difficult to produce at constant speed and high energy costs.

In the case of stepper motor drive, the best efficiency, lowest energy costs and precise positioning are the main advantages. Its disadvantages are the low speed, more complicated control in a non-computer environment, and a larger weight with the same power, which adversely affects the dynamics of the system.

Advantages of the toothed belt drive: it provides easy-to-manufacture and install energy transmission, works with good efficiency (90-98 \%), allows precise synchronous drive. Its main disadvantage is the weaker position control.

Through all of these, we have implemented a mechanical system and a modeling and simulation procedure, the modularity of which allows the comparison of different solutions for kinematic and dynamic purposes, mostly for educational purpose.

\section{References}

[1] Forgó Z.: Bevezetés a Mechatronikába. Erdélyi Múzeum-Egyesület, Kolozsvár, 2009. https://doi.org/10.36242/mtf-06

[2] Antal H., Aradi P., Czmerk A., Lakatos B., Chován T. és Varga T.: Mechatronikai berendezések tervezése. Kiadó BME MOGI, TÁMOP-4.1.2.A/1-11/1-2011-0042 projekt keretében készült, 2014.

[3] Bencsik A.: Mechatronika alapjai. Óbudai Egyetem, Bánki Donát Gépész és Biztonságtechnikai Mérnöki Kar, TÁMOP-4.1.2.A/1-11/1-2011-0054 projekt keretében készült, Budapest, 2014. 